\title{
Jogos de amor e de espectador
}

\section{Carolina Oliveria do Amaral}

Doutoranda em Comunicação Social pelo PPGCOM-UFF, na linha de pesquisa Estudos de Cinema e Audiovisual. Roteirista e pesquisadora que atua no campo de Roteiro, Narrativa e Cinema de Gênero.
Resumo: A aproximação da ideia de narrativa e jogo proposta por Iser é referenciada pelo texto que tensiona outra relação já antiga: a de amor e jogo. O objetivo é a análise de comédias românticas contemporâneas, um gênero popular que com frequência se utiliza de triângulos amorosos como trama. Tendo a triangulação autor-texto-leitor interconectada num jogo, é trazida a triangulação de narrativas românticas que se coloca também em jogo com o leitor. Por fim, analisa-se o filme Casa comigo (Leap Year, 2010) para entrelaçar as questões levantadas.

Palavras-chave: Amor; Jogo; Espectador; Narrativa; Comédia romântica.

\section{Title: Love and spectator games}

Abstract: The approach of the idea of narrative and game proposed by Iser is referred in the text that tensions another long-standing relationship: love and game. The aim is the analysis of contemporary romantic comedies, a popular genre that frequently uses love triangles as major plot. Having the triangulation between author-text-reader interconnected in a game, it brings the triangulation of romantic narratives that also brings itself into play with the reader. Finally, the movie Leap Year (2010) is analyzed to intertwine the issues raised.

Keywords: Love; Game; Spectator; Narrative; Romantic comedy. 


\section{O Jogo: do amor cortês ao amor romântico}

O que filmes como O Arrasador de Corações (L'arnacoeur, 2010), Qualquer gato vira-lata (2011) e Casa comigo (Leap Year, 2010) têm em comum? Apesar das diferenças entre países, línguas, diretores e orçamentos, os três são filmes contemporâneos, cuja narrativa principal privilegia o amor romântico heterossexual. Podemos dizer também que os filmes fazem parte do gênero cinematográfico "comédia romântica", que tem por convenção a união do casal depois de uma tortuosa trilha de engraçados desencontros. Ao analisarmos mais profundamente as tramas, percebemos que os filmes constroem o processo de sedução e enlace através de um triângulo amoroso em que a mulher é disputada por dois homens. O formato é antigo, porém os motivos e as maneiras colocadas em disputa são renovadas e se diferenciam entre si.

${ }^{1}$ Howard Bloch, Georges Duby, Antony Giddens, Paul Sutton e a própria Marilyn Yalom apontam o estudo de Denis de Rougemont como o seminal em localizar a "invenção", a "descoberta" ou a "revelação" do amor romântico nessa época, que ditou comportamentos e cortesias, expectativas e simbolismos que até então não existiam, e sobrevivem até hoje atualizando a ideia de fascinação romântica.
Histórias com triangulação amorosa remetem à própria história do amor romântico na sociedade ocidental. Alguns estudos ${ }^{1}$ indicam que o amor como conhecemos hoje, chamado primeiramente "cortês", surgiu nas cortes francesas do século XII, primeiro no Sul, depois no Norte, num momento que muitos chamam de "Renascença do século XII", um período fértil em mudanças:

Junto com o renascimento das cidades, a volta do dinheiro, e o crescimento de um comércio de longa distância com o Oriente [...] ocorreu a mudança mais significativa na articulação do feminino e do sexo, desde a invenção patrística dos gêneros sexuais na era cristã. Como C. S. Lewis, Robert Briffault, Denis de Rougemont, Reto Bezzola, Irving Singer, e outros afirmam, a noção de fascinação romântica que governa o que dizemos sobre o amor, o que dizemos àqueles que amamos, o que esperamos que eles nos digam (e dizer que eles dizem), como agimos e esperamos que eles ajam, como negociamos nossa relação com o social - em resumo, a higiene que governa a nossa imaginação erótica até a escolha de quem amamos e as posições físicas para exprimir isso - não existia na tradição judaica, germânica, árabe ou hispânica, na Grécia ou na Roma clássica, ou no início da Idade Média. $\mathrm{O}$ amor romântico tal como o conhecemos não surgiu até aquilo que algumas vezes se chama a renascença do século XII. (BLOCH, 1995, p. 16).

Entre tantas mudanças, os autores ressaltam a noção e as regras de amor que surgiram naquela época. Ao invés de raptar, seria preciso seduzir as mulheres seguindo as boas regras do amor cortês. A cortesia era seguida polidamente por nobres de ambos os sexos, e promovia o amor idealizado cantado por trovadores e menestréis. "Um jogo", diz Duby (2013, p. 341): "eles esforçavam-se por conter as violências do ataque sexual no quadro de um ritual, o de um divertimento mundano, o amor novo celebrado pelos poetas". Era o amor cortês, termo que traduziu o fin'amor:

Uma nova visão das relações de amor entre os sexos, a qual surgiu primeiro nas canções e depois na escrita, viria a evoluir em modelo para (quase) todos os homens e mulheres do Ocidente, com ou sem o componente do adultério. Hoje damos a ela o nome de amor romântico.(YALOM, 2013, p. 23).

O amor cortês proporcionou uma verdadeira revolução nas sensibilidades e nas expectativas de nobres homens e mulheres dispostos a correr riscos para viver uma paixão. As histórias de amor eram cantadas em toda região através dos lais, pequenos poemas narrativos ou líricos com o acompanhamento de harpa. Dispostos a se tornarem parceiros no jogo cortês do amor, homens e mulheres da aristocracia passaram a usar o xadrez como "um espaço onde eles podiam lidar tanto com seus sentimentos como com as artimanhas do jogo" (Ibid., p. 30). Duby (2013) e Yalom (2013) destacam a importância do jogo nas cortes europeias, já que no jogo do amor a rainha também era a peça principal, e "o xadrez consistiu numa metáfora perfeita do amor entre a nobreza" (Loc. cit.). 
${ }^{2}$ Pouco se sabe de Marie de France, além de que morou na Inglaterra. Muito provavelmente nasceu na França, e escreveu 12 lais de amor que sobreviveram até nós.
${ }^{3}$ Uma espécie de espetáculo da retórica, esses diálogos ajudam a espetacularizar o fabuloso ato de apaixonar-se, e são a parte mais importante no processo narrativo. Não à toa, esse tipo de narrativa só foi possível a partir dos anos de 1930, quando o cinema sonoro era uma realidade.
As histórias geralmente contavam com três personagens principais: o cavaleiro, valente e apaixonado, disposto a ser leal ao rei e ao seu amor; a dama, dona de todo amor e devoção do cavaleiro; e o rei, soberano e marido. As convenções determinavam só ser possível o amor romântico fora do casamento, uma instituição planejada para os negócios entre as cortes da Europa ocidental.

Um dos escritores mais iminentes da época foi Chrétien de Troyers, com poemas narrativos que tematizavam os romances de cavalaria, enfatizando tanto as aventuras do herói quanto os percalços amorosos em que estava envolvido. Foi Chrétien quem recriou o mito de Guinevere, Arthur e Lancelot na estrutura de um triângulo amoroso. Lancelot, cavaleiro mais valente e leal ao rei Arthur, irremediavelmente sofre de um amor correspondido pela rainha, Guinevere. Lancelot, o cavaleiro da charrete, de Chrétien, é o modelo paradigmático para todos os poemas de amor da época, incluindo os lais de Marie de France ${ }^{2}$ sobre os amantes e suas provações para consumir esse amor.

Donald Maddox (apud SHUMWAY, 2003, p. 399) analisou os lais de Marie de France, e identificou uma estrutura narratológica trídica, com um par de sujeitos e um terceiro sujeito excluído: "a sucessão narrativa ocorre porque sempre o terceiro excluído quer ser incluído no par. Se ele ou ela for excluído, necessariamente desloca-se a outra pessoa". Assim, a narrativa encadeia arranjos e rearranjos do par amoroso a cada revolução do triângulo no formato de um romance.

David Shumway (2003) se apropria dessa mesma estrutura para analisar filmes de comédias românticas da década de 1930, as chamadas screwball comedies, primeiro ciclo de comédias românticas faladas que Hollywood produziu. Também baseado na idealização de um amor heterossexual que deveria ser conquistado por aventuras, essas narrativas, ao contrário das histórias medievais, usariam o triângulo amoroso como forma de mistificar o casamento, escolhido como desfecho principal.

Se voltarmos aos três filmes citados, observamos a mesma relação triangular em que os protagonistas não são nem nunca foram um casal, mas por circunstâncias particulares em cada filme, passam a conviver tendo em vista que em breve as mulheres, nas três histórias, estarão casadas com outra pessoa.
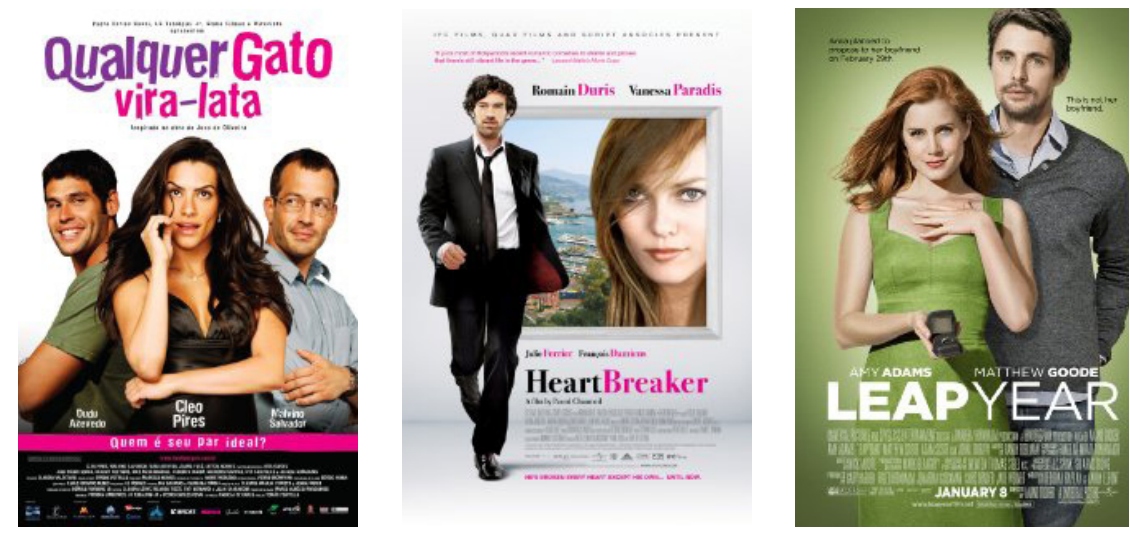

Figura 1: Os três cartazes posicionam protagonistas em primeiro plano e os outros personagens mais atrás. Apenas o cartaz brasileiro evidencia o triângulo amoroso

Ao contrário dos poemas do século XII, em que os principais entraves à consumação do amor são externos, como a sociedade e o marido traído, nessas comédias os obstáculos são internos. É uma convenção do gênero que o romance se construa por meio de "fogos de artifícios verbais"3 entre indivíduos que ainda não são felizes para sempre: "somos convidados a participar de um relacionamento verbal entre os dois. As trocas verbais funcionam principalmente para criar um 
senso de atração e eletricidade" (ibid., p. 404). Não há lugar para confissões de amor até que se esteja bem perto do final, para desmontar o triângulo e afastar de vez o terceiro sujeito. Shumway (ibid., p. 400) acredita que o espectador, ou o leitor do romance, é colocado nessa posição de excluído da estrutura triangular como a pessoa estranha ao par amoroso; "o espectador experencia uma ausência, e o resultado motiva sua atenção".

Podemos dizer que, ao sentir-se dentro, ainda que numa posição externa ao triângulo da história, o espectador estaria, por isso mesmo, fazendo parte do jogo. Se a cortesia for um jogo que "como se sabe, joga-se a três, a dama, o marido, o amante e a dama é sua peça principal" (DUBY, 2013, p. 341), e as histórias de amor se apropriam dessa estrutura, acreditamos que o leitor/espectador dessas histórias é colocado também em jogo. Shumway fala numa identificação pela ausência, mas primeiro falaremos sobre a presença do espectador, uma peçachave para estabelecer a relação autor-texto-leitor "intimamente conectados numa relação a ser concebida como um processo em andamento que produz algo que antes inexistia" (ISER, 2007, p. 105).

Wolfgang Iser se aventura a pensar "uma tentativa de dispor o conceito de jogo sobre a representação, enquanto conceito capaz de cobrir todas as operações levadas a cabo no processo textual" (ibid., p. 107). A intenção é valorizar o caráter performativo das narrativas:

Os autores jogam com os leitores e o texto é um campo de jogo. O próprio texto é o resultado de um próprio ato intencional pelo qual um autor se refere e intervém em um mundo existente, mas, conquanto o ato seja intencional, visa a algo que ainda há de ser identificado e que é esboçado de modo a incitar o leitor a imaginálo e, por fim, a interpretá-lo. Essa dupla operação de imaginar e interpretar faz com que o leitor se empenhe na tarefa de visualizar as muitas formas possíveis do mundo identificável, de modo que, inevitavelmente, o mundo repetido no texto começa a sofrer modificações. Pois não importa que novas formas o leitor traz à vida: todas elas transgridem - e daí, modificam - o mundo referencial que tem no texto. Ora, como o texto ficcional automaticamente invoca a convenção de um contrato entre autor e leitor, indicador de que o mundo textual há de ser concebido, não como realidade, mas como se fosse realidade. Assim o que quer que seja repetido no texto não visa a denotar o mundo, mas apenas um mundo encenado. Este pode repetir uma realidade identificável, mas contém uma diferença decisiva: o que sucede dentro dele não tem as consequências inerentes ao mundo real referido. Assim, ao se expor a si mesma a ficcionalidade, assinala que tudo tão-só de ser considerado como se fosse o que parece ser; noutras palavras, ser tomado como jogo. (Loc. cit.).

O espectador, em jogo, é estimulado imaginativamente pelo texto fílmico. Murray Smith (2001) lembra que "ilusão" é a metáfora ideal para a mímese, e acreditamos que "jogo" seria para a imaginação, e por isso é mais adequado à espectatorialidade. A ficção nos permite, enquanto espectadores, viver - nos termos de Smith - "quase-experiências", expandindo e explorando experiências vividas e imaginadas a partir do que vemos na tela. Além disso, o espectador está consciente de que seu envolvimento com o filme é temporário. $O$ espectador participa imaginativamente e consciente de que se trata de uma ficção, um jogo.

${ }^{4} \mathrm{O}$ autor usa "poesia" e "poético" num "sentido amplo e radical" compreendendo também o que chamamos de "literatura" e "literário". Estendemos também ao cinema porque o próprio autor aproxima a leitura à espectatorialidade, ao equiparar escrita e "meios eletrônicos, auditivos e audiovisuais".
Por outro lado, o caráter performático do jogo chama a atenção para a dimensão corpórea intrínseca à performance. Paul Zumthor (2007) entende que a leitura é uma performance, porque é através dela que o texto se encena, encontrando o corpo necessário à sua voz:

Todo texto poético ${ }^{4}$ é, nesse sentido, performativo, na medida em que aí ouvimos, e não de maneira metafórica, aquilo que ele nos diz. Percebemos 
a materialidade, o peso das palavras, sua estrutura acústica e as reações que elas provocam em nossos centros nervosos. Essa percepção, ela está lá. Não se acrescenta, ela está. É a partir daí, graças a ela que, esclarecido ou instilado por qualquer reflexo semântico do texto, aproprio-me dele, interpretando-o, ao meu modo; é a partir dela que, este texto, eu o reconstruo, como o meu lugar de um dia. (p. 54).

O encontro entre leitor e obra acontece de uma maneira pessoal. "A obra, a rigor, é um conjunto de efeitos possíveis sobre um fruidor" (GOMES, 1996, p. 102). A espectatorialidade enquanto performance permite que se vibre com $o$ próprio corpo os caminhos do texto fílmico:

O texto poético aparece, com efeito, a esses críticos, como um tecido perfurado de espaços brancos, interstícios a preencher, Lehrstellen, disse um, Unbestimmtheistellen, segundo o outro, "passagens de indecisão" exigindo a intervenção de uma vontade externa, de uma sensibilidade particular, investimento de um dinamismo pessoal para serem, provisoriamente, fixadas ou preenchidas. O texto vibra; o leitor o estabiliza, integrando-o àquilo que é ele próprio. Então é ele que vibra, de corpo e alma.(Ibid., p. 52-53).

Assim, Zumthor (2007) enfatiza que a comunicação poética não pretende apenas passar uma informação, mas tenta mudar aquele a quem se dirige. Iser também sinaliza que o jogo "converte o texto em uma matriz geradora para produção de algo novo" (Ibid., p. 112). Para além do prazer da fruição e de obter experiências por meio do que não é familiar, Iser resguarda à encenação própria do jogo com o leitor "um meio de transpor fronteiras":

Em termos filogenéticos, o jogo, no reino animal, começa quando se expande o espaço do habitat. A princípio, parece ser uma atividade que tem seu fim em si mesma, explorando os limites do possível, em vista do fato de que agora tudo é possível. Mas também podemos vê-lo como uma suposta ação ou como uma experiência que prepara o animal para enfrentar o imprevisível por vir. Quanto mais se expande o território do animal, tanto mais importante e, certas vezes, mais deliberado se torna o jogo como um meio de preparação para a sobrevivência. (ZUMTHOR, 2007, p. 117).

O jogo permite uma preparação para experiências que virão, por se tratar de "um meio para avaliarmos nossas prováveis respostas emocionais a situações hipotéticas e apreciarmos os sentimentos de outras pessoas, passando por situações que ainda não tivemos a possibilidade de experimentar" (TAYLOR apud SMITH, 2005, p. 40). Essa potência imaginativa só se alcança por se tratar de um jogo, ou como Smith fala, por esse envolvimento acontecer na instituição da ficção. Dessa forma, o jogo permite nos tornar presentes a nós mesmos através da atividade imaginativa, e ao mesmo tempo ausentes, exatamente por se tratar de um jogo. Nas palavras de Iser (2002), "a transformação é um caminho para o inacessível, mas a transformação encenada só torna acessível o inacessível. Seu alcance talvez seja o mais prazenteiro" (p. 118).

Assim sendo, é por estar presente e ausente no triângulo amoroso que o espectador sente prazer ao vivenciar a história. Os filmes citados participam de um gênero cinematográfico, com preâmbulos narrativos, protocolos estéticos e práticas contextuais específicas, ou seja, partilham regras próprias dentro do jogo da ficção.

\section{Jogo e gênero cinematográfico}

O conceito de jogo para análises de cinema comercial vem ao encontro de teorias da recepção que ressaltam o caráter criativo e produtor da atividade espectatorial. 
Ao falarmos em jogo, trazemos à tona termos como "performance" e "imaginação" em contraste com sujeição e ilusão, que salientam uma tendência "ilusionista" do cinema de gênero que sujeitaria o espectador à ideologia dominante. Ao contrário, o jogo abre possibilidades ao leitor/espectador capaz de vivenciar, de se entreter imaginativamente, de antecipar soluções. Existe também a possibilidade de, como num jogo, num faz-de-conta, se familiarizar situações novas a partir das "quaseexperiências" vividas emocionalmente no contato com a ficção. O espectador joga com o filme na mesma medida em que é jogado por ele.

Rick Altman (1999) sugere que filmes de gênero solicitam participações compartilhadas para serem percebidos enquanto tal: "gêneros cinematográficos não são o mundo real, mas um jogo que jogamos com jogadas e jogadores emprestados do mundo real" (p. 157). O autor pontua ainda que a opção por um gênero específico não é uma mera escolha de compra, pois "o contrato genérico envolve aderência a códigos particulares e, assim, identificação com outros que também aderem" (Ibid., p. 161). Devido aos códigos partilhados, o autor acredita que num cinema de gênero não haja apenas uma comunicação entre espectador e texto fílmico, ao que ele chama de "comunicação frontal". Para ele, o gênero envolve também outros espectadores que aderem aos mesmos códigos e gozam de um mesmo prazer estando em contato com aqueles filmes. Existiria, portanto, uma comunicação lateral entre membros de uma mesma comunidade genérica. Altman chama esse tipo de comunicação de "comunidades consteladas".

Em relação às comédias românticas recentes, uma série de expectativas quanto à história, personagens e convenções são aguardadas por espectadores que antecipam e se surpreendem com a maneira como os filmes se encadeiam. "Fator primordial na unificação de uma comunidade constelada, o processo de espectatorialidade se torna um método simbólico de comunicação com os outros membros daquela comunidade" (Loc. cit.). Existe uma relação semântico-sintática guiada pela produção (production-driven), e também uma relação lateral entre espectadores guiada para a recepção (reception-driven). Segundo Altman, o filme de gênero só existe numa intercessão entre esses dois eixos.

Nos três filmes citados no início do artigo, o espectador habituado ao gênero, quiçá um que participe dessa comunicação lateral com outros membros, espera uma história de amor que se desnovela com humor, tendo o enlace amoroso como clímax. As convenções determinam um encontro inusitado do casal principal, desentendimentos e tensão sexual que se resolvem num final feliz. Os três filmes apresentam todos esses elementos esperados, todos eles jogam com expectativas, desenvolvimento de problemas e soluções. A despeito das diferenças culturais, orçamentárias e escolhas pessoais, o gênero cinematográfico "comédiaromântica" - de inspiração hollywoodiana - condensou expectativas num filme brasileiro, francês ou irlandês-estadunidense que circula pelo mundo. As três histórias apresentam um triângulo amoroso que se modifica a cada revolução

${ }^{5}$ David Shumway e Robert Mckee mostram que o engajamento do público pelo casal "correto", além de se construir narrativamente, muitas vezes já fica claro pelo casting: sabemos pelos astros principais quem ficará junto a partir do cartaz do filme. "Não podemos imaginar Rosalind Russel apaixonada por Ralph Bellamy em Jejum de Amor (His Girl Friday, Howard Hawks, 1940, EUA). Queremos que ela fique com Cary Grant do momento em que eles se encontram no escritório no início do filme. Esses filmes sempre nos dizem cedo para quem devemos torcer" (SHUMWAY, 2003, p. 403). no par. Os três filmes terminam com beijos apaixonados e o casal "certo" 5 junto.

Mesmo com convenções e expectativas em comum, os três filmes são bastante diferentes entre si. Isso acontece porque o cinema de gênero procura combinar os prazeres da familiaridade com o inabitual, "tendo como base tanto convenções estabelecidas como afastamentos com relação a elas" (SMITH, 2001, p. 168). Daí a eficácia de conceitos como imaginação e jogo na análise dos filmes, porque enfatizam "a singularidade dos personagens e narrativas ficcionais" (Loc. cit.) sem negligenciar os elementos extratextuais próprios do gênero.

Os filmes apresentados são "comédias de conquista" em que a união do casal se constrói narrativamente. Faz parte do engajamento pela história não apenas o encantamento entre o casal principal, mas também o fascínio que ele exerce no espectador. É claro que alguns espectadores irão se afetar mais que outros, porque alguns são melhores leitores do gênero que outros. Algo que se aproxima 
do que Umberto Eco chama de "leitor-modelo", um conjunto de capacidades que o texto, quando formulado, intui para o leitor.

Altman também reconhece que espectadores sofrem "tentações genéricas", uma transgressão proporcionada pela experiência com o gênero. Ao analisar a comédia musical O Picolino (Top Hat, Mark Sandrich, EUA, 1935), o autor evidencia a torcida do espectador para que Ginger Rogers e Fred Astaire dancem juntos, se apaixonem e fiquem juntos, ainda que ela pense ser ele casado com sua melhor amiga. O mesmo acontece quando perto do fim, Rogers, agora casada, sai para um passeio de barco com Astaire:

Encontramo-nos abertamente celebrando a consumação emocional de um caso amoroso adúltero, para que possamos desfrutar do contínuo acesso ao prazer genérico. Quando estamos no mundo, seguimos suas regras. Quando entramos no mundo dos gêneros, revelamos gostos e tomamos decisões de uma natureza inteiramente diferente. (Ibid., p. 147).

Mesmo que imaginária e temporária, a experiência genérica promove uma quebra de normas culturais particulares. É uma "oportunidade autorizada de atividade contra-cultural, embora dentro do contexto criado pela própria cultura", assim como parques de diversões, carnavais e eventos esportivos (Ibid., p. 156).

Atitudes e sentimentos explorados pelo cinema de gênero, como pavor, tortura, sofrimento, crime, traição, entre outros, trariam um prazer genérico exatamente por serem banidos da nossa cultura. Assim, "cada gênero começa posicionando uma norma cultural, de maneira a permitir a construção do prazer genérico contradizendo essa norma" (Ibid., p. 157). Em comédias românticas, assim como em comédias musicais e screwball comedies, a norma colocada é o casamento, ou pelo menos a felicidade conjugal aparente do casal que começa junto. A partir daí, o filme desconstrói esse casal com o surgimento de um terceiro elemento, o amante, que conquistará o coração da dama e ficará com ela no final.

Se nos romances de cavalaria, nos lais, ou na história de Tristão e Isolda, o amor só poderia acontecer fora do casamento, e apenas a morte poderia juntar os dois amantes para sempre, nas comédias românticas contemporâneas o romance fora do casamento - ou noivado, como é mais comum, com um casamento batendo à porta - serve apenas para selar uma nova união, o casamento "certo" que se concretiza ao final da história. A morte dá lugar ao compromisso nesse tipo de romantismo dos séculos XX e XXI. Dos três filmes contemporâneos mencionados, nenhum desenvolve melhor essas questões que Casa Comigo, o qual detalharemos em seguida.

\section{Casa Comigo}

Em acordo com as análises de Altman, Casa Comigo começa colocando uma situação em que a narrativa vai completamente quebrar em favor do prazer genérico: Anna (Amy Adams) e Jeremy (Adam Scott) participam de uma entrevista com proprietários de um imóvel que pretendem comprar. Em sua última resposta, Anna, segura e confiante, diz:

eu morei em Boston a vida toda. Sempre sonhei em morar aqui e, felizmente, encontrei alguém que divide esse sonho comigo. E garanto que vocês não vão encontrar duas pessoas mais apropriadas às suas altas exigências e, se me permitem a ousadia, o seu gosto refinado. (CASA..., 2010).

Anna e Jeremy namoram há 5 anos e planejam comprar o imóvel, embora não tenham conversado sobre casamento ainda. 
Logo após a entrevista, Jeremy viaja a Dublin para um congresso. Anna decide visitar o namorado e pedi-lo em casamento, pois dali a três dias seria 29 de fevereiro, e uma tradição irlandesa permite que mulheres propusessem casamento a seus noivos nesse dia. Anna viaja, porém uma série de catástrofes naturais a impedem de ir direto a Dublin. Após pegar um avião, um carro e um barco, ela finalmente chega a Dingle, onde conhece Declan (Matthew Goode) que, por uma alta quantia, aceita dirigir até Dublin, apesar de odiar a capital do país.

Declan e Anna se mostram totalmente inadequados um para o outro, e parecem odiar a companhia. Além de implicâncias e briguinhas, uma série de infortúnios, como vacas na estrada, a perda do carro, ladrões e cachorros raivosos, entre outros, atrasam a viagem por dois dias. A jornada é construída a partir dos eventos que dão errado, mas que, ao mesmo tempo, mantêm o casal junto. Há uma tensão sexual inerente às brigas e discussões, própria do gênero, bem como disfarces e mal-entendidos. Por uma noite, Declan e Anna fingem ser casados para conseguirem se hospedar numa pousada no interior. Os dois se aproximam e se beijam; na tensa noite que dividem a cama, sem que nada aconteça, segue um domingo no interior, sem a menor tentativa de chegar a Dublin: eles estão gostando de passar esse tempo juntos.

A ausência de Jeremy durante toda a exótica aventura funciona de modo a fazer o triângulo andar. Se, por um lado, Declan e Anna ficam a maior parte do tempo a sós, por outro, quando eles parecem se acertar e se aproximar, Jeremy retorna por meio de um telefonema, e o casal original se refaz. É essa dinâmica trídica que mantém o jogo também com o leitor, presente e ausente simultaneamente na trama. "Quanto mais o leitor é atraído pelos procedimentos de jogar o jogo do texto, mais é ele também jogado pelo texto" (ISER, 2007, p. 115).

A trama amorosa engaja o espectador pelo romance entre Anna e Declan, que aos poucos transforma "fogos de artifícios verbais" em conversas íntimas e amizade sincera. Declan chega a dizer "sou seu servo esperando as ordens" (CASA..., 2010), fazendo referência aos cavaleiros amantes e servos de suas damas, embora em tom jocoso. Krutnik (2002) observa em comédias românticas atuais uma "ardente e até irônica possibilidade de romance" em diálogo constante com "notas românticas de textos passados" (p. 139).

Os dois saem transformados da viagem, e quando finalmente chegam a Dublin, Jeremy aparece e propõe Anna em casamento, antes mesmo que ela o contasse seus planos, que pareciam ter mudado, quando ela, antes de responder sim, claramente hesita e olha para Declan, que já foi embora.

${ }^{6} \mathrm{~A}$ inspiração para a temporalidade do quase vem de Linda Williams, que denomina "gêneros do corpo" o horror, o melodrama e o pornô, no qual o espectador sentiria na pele o pavor, as lágrimas e o gozo dos gêneros. Ainda segundo a autora, cada gênero construiria suas histórias a partir de uma temporalidade própria: no horror, as coisas aconteceriam cedo demais (too early), no melodrama tudo é tarde demais (too late), enquanto no pornô as coisas aconteceriam no tempo certo (on time). Acreditamos que a comédia romântica se constrói a partir do quase, a forte expectativa de desenlace amoroso, o magnetismo da espera pelo êxtase alcançado apenas no fim.
Apesar de Altman (1999) reconhecer os prazeres contra-culturais do gênero, que em Casa Comigo constroem o envolvimento amoroso extra-conjugal, o autor lembra que os gêneros fazem parte de uma estrutura conservadora que combina "um longo período de intensificação com uma rápida e definitiva restauração dos valores culturais" (p. 155). No filme, a restauração se faz via o rompimento de Anna com Jeremy, após descobrir que o pedido era apenas para conseguir comprar o tal apartamento, e um novo pedido de casamento é proposto, agora por Declan. A resolução e consequente restauração de valores acontecem de maneira rápida, se compararmos à longa jornada de prazeres genéricos da conquista.

Existe um pacto com o espectador de que a demora na resolução do conflito amoroso é justamente o motivo de prazer da tentação genérica. Quanto mais longa a espera, mais potente o enlace final desejado pelo espectador. É convenção em comédias românticas a resolução amorosa acontecer apenas no final, com um beijo apaixonado. Ao longo da história, surgem sucessivas encruzilhadas em que o par romântico reafirma suas afinidades, porém posterga a decisão de ficarem juntos. Podemos dizer que a comédia romântica trabalha a temporalidade do quase $^{6}$ ao longo da história, a constante negação da satisfação que só pode 
${ }^{7}$ Queremos ressaltar aqui o poder da leitura, que ao longo do tempo normalmente reconforma e descobre novos jogos que o texto trazia, mas que permaneciam encobertos. No cinema, por exemplo, foram as leituras feministas que posteriormente viram os melodramas como um importante foco de protagonismo para as mulheres, e não apenas local de submissão, e as leituras queers de divas do musical, que ressignificaram o texto estelar de figuras como Judy Garland e Lisa Minelli. ocorrer no final. Em Casa comigo, eles quase se encontram, ela quase se declara pra ele, ele quase desiste de tudo, até que, por fim, eles quase não ficam juntos, mas tudo se acerta no último beijo de amor.

A temporalidade do quase faz parte do jogo do texto com o leitor, que até sente prazer na demora, e mais ainda no desfecho: "o processo de fazer previsões constitui um aspecto emocional necessário da leitura que coloca em jogo esperanças e medos, bem como a tensão resultante de nossa identificação com o destino das personagens" (ECO, 2009, p. 58).

O quase se aproxima do que Umberto Eco (Loc. cit.) chama de "tempo de trepidação", que seria aquilo que retarda um final dramático. O tempo de trepidação está diretamente ligado ao delectatio morosa, "uma demora concedida até mesmo àqueles que sentem a necessidade premente de procriar", delongas que a literatura permite fazer, inclusive abandonando a cena contada para desfrutar de "passeios inferenciais", como se divagasse pelo bosque. "Porque demorar-se no supérfluo é a função erótica do delectatio morosa" (Ibid., p. 64).

A relação entre tempo de trepidação e recompensa para o espectador é proporcional, pois "se tivessem de esperar menos tempo e se sua trepidação fosse menos intensa, a catarse não seria tão completa" (Ibid., p. 71). Chegamos assim no ponto final do jogo entre texto-autor-leitor. Através da fruição, o espectador joga o jogo do texto fílmico, que por sua vez já construiu o modo como a obra será recebida7. Willson Gomes (1996) lê a Poética de Aristóteles com ênfase em seu caráter "pragmático", no que diz respeito à recepção. A apreciação estética passaria por "um modo ativo e operativo de execução", "fazer acontecer o efeito próprio da obra é restituí-lo à vida" (Ibid., p. 104). A catarse faria parte do efeito prazeroso proposto pela tragédia, que sugere "a transformação por arte das emoções 'físicas' - desagradáveis - em emoções 'artísticas' e 'estéticas'” (Loc. cit.). Na comédia romântica, o efeito que se pretende alcançar com a temporalidade do quase e os prazeres da demora celebram, por fim, sua súbita e definitiva resolução narrativa: o arrebatamento de uma experiência amorosa.

Krutnik (2002, p. 140) adverte que as comédias românticas atuais "insinuam que antes de ser uma coisa que acontece com as pessoas, o amor é essencialmente o produto de uma fabricação estética", dada a ênfase na "relação lúdica que o filme constrói com seu público". O público se apaixona pelo filme, sabendo ser esse o efeito pretendido desde o início pelo jogo da comédia romântica. 0 triângulo mulher-marido-amante serve para ressaltar os laços de amor entre o casal apaixonado assim como a tríade texto-autor-leitor joga para que leitor e texto (fílmico) se unam e vivam juntos e felizes para sempre.

\section{Referências Bibliográficas}

ALTMAN, R. Film/Genre. Londres: BFI, 1999.

BLOCH, R. H. Misoginia medieval e a invenção do amor romântico. Rio de Janeiro: Editora 34, 1995.

CASA comigo? Direção: Anand Tucker. Estados Unidos: Universal Pictures, 2010. (100 min.). son., color.

COMO arrasar um coração. Direção: Pascal Chaumeil. França: Quad Productions, 2011. (105 min.). son., color.

DUBY, G. As damas do século XII. São Paulo: Companhia das Letras, 2013. 
ECO, U. Seis passeios pelos bosques da fiç̧ão. São Paulo: Companhia das Letras, 2009.

ISER, W. O Jogo do texto. In: LIMA, L. C. (Org.). A literatura e o leitor: textos da teoria da recepção. Rio de Janeiro: Paz e Terra, 2002.

GOMES, W. Estratégias de produção de encanto - o alcance contemporâneo da poética de Aristóteles. Textos de cultura e comunicação, n. 351996.

MCKEE, R. Story: substância, estrutura, estilo e os princípios da escrita de roteiros. Curitiba: Arte \& Letra, 2006.

KRUTNIK, F. Conforming passions: Contemporary Romantic Comedy. In: NEALE, Steve. (Ed.). Genre and contemporary hollywood. Londres: BFI, 2002.

QUALQUER gato vira-lata. Direção: Tomas Portella; Daniela De Carlo. Rio de Janeiro: Buena Vista International, 2011.

SHUMWAY, D. R. Screwball comedies: constructing romance, mystifying marriage. In: GRANT, B. K. (Org.). Film genre reader III. Austin: University of Texas Press, 2003.

SMITH, M. Espectatorialidade cinematográfica e o estatuto da ficção. In: RAMOS, F. (Org.). Teoria contemporânea do cinema volume I. São Paulo: SENAC, 2005.

SUTTON, P. Après le coup de foudre: narrative, love and spectatorship in groundhog day. In: ABBOTT, S.; JERMYN, D. (Eds.). Falling in love again: romantic comedy in contemporary cinema. Londres e Nova lorque: I.B. Tauris, 2009.

YALOM, M. Como os franceses inventaram o amor: nove séculos de romance e paixão. São Paulo: Prumo, 2013.

ZUMTHOR, P. Performance, recepção, leitura. São Paulo: Cosac Naify, 2007. 